\title{
A novel three-way Philadelphia Variant t(9;22;17)(q34;q11.2;q12) in chronic myeloid leukemia: A case report
}

\author{
KATHY ALLEN-PROCTOR, ELIZABETH RUCKDESCHEL and RANA NAOUS \\ Department of Pathology, State University of New York-Upstate Medical University, Syracuse, NY 13210, USA
}

Received May 12, 2017; Accepted November 23, 2017

DOI: $10.3892 / \operatorname{mco} .2017 .1529$

\begin{abstract}
Chronic myeloid leukemia (CML) is a hematologic malignancy associated with increased circulating myeloid cells and platelets in the peripheral blood, with accompanying bone marrow hyperplasia. The Philadelphia chromosome, $\mathrm{t}(9 ; 22)(\mathrm{q} 34 ; \mathrm{q} 11)$, is present in $95 \%$ of CML patients, resulting in constitutive tyrosine kinase activity; however, $5 \%$ of CML patients possess a Philadelphia variant. A novel three-way Philadelphia translocation variant, $\mathrm{t}(9 ; 22 ; 17)(\mathrm{q} 34 ; \mathrm{q} 11.2 ; \mathrm{q} 11.2)$, was identified in a 54-year old man who presented with leukocytosis, anemia and thrombocytosis that was diagnosed with chronic myeloid leukemia, chronic phase. Cytogenetic analysis by G-banding revealed the presence of a three-way translocation involving the long arms of chromosomes 9, 22 and 17. Fluorescence is situ hybridization utilizing a dual-color fusion probe confirmed the presence of the Bcr-Abl fusion gene.
\end{abstract}

\section{Introduction}

Chronic myeloid leukemia (CML) is a hematologic malignancy associated with increased circulating myeloid cells and platelets in the peripheral blood, with accompanying bone marrow hyperplasia. The Philadelphia chromosome, $\mathrm{t}(9 ; 22)(\mathrm{q} 34 ; \mathrm{q} 11)$, is present in $95 \%$ of CML patients, and is the result of a balanced translocation between the long arms of chromosome 9, harboring the Abl protooncogene, and chromosome 22, harboring the Bcr protooncogene $(1,2)$. The resulting chimeric Bcr-Abl gene leads to constitutive tyrosine kinase activity. Approximately 5\% of CML patients possess a variant of the Philadelphia chromosome (2). Here we describe a patient with chronic phase CML who presented with a novel three-way $(9 ; 22 ; 17)(\mathrm{q} 34 ; \mathrm{q} 11.2 ; \mathrm{q} 11.2)$ Philadelphia chromosome translocation.

Correspondence to: Dr Kathy Allen-Proctor, Department of Pathology, State University of New York-Upstate Medical University, 750 E Adams Street, Syracuse, NY 13210, USA

E-mail: allenprm@upstate.edu

Key words: chronic myeloid leukemia, Philadelphia variant, novel translocation

\section{Case report}

In January of 2017, a 54 year old man was transferred to our institution from an outside facility with leukocytosis, anemia, and thrombocytosis. His hematologic parameters were as follows: White blood cells $84.2 \mathrm{~K} / \mathrm{ul}$, red blood cells $3.96 \mathrm{M} / \mathrm{ul}$, hemoglobin $10.5 \mathrm{~g} / \mathrm{dl}$, hematocrit $32.1 \%$, red cell distribution width $19.0 \%$, and platelets $641 \mathrm{~K} / \mathrm{ul}$. A peripheral blood film showed increased polychromasia and increased anisocytosis and poikilocytosis, with acanthocytes, schistocytes, dacryocytes, and elliptocytes identified. There was a left shift in the peripheral granulocyte population, with a manual differential count finding $1 \%$ blasts, $1 \%$ promyelocytes, $11 \%$ myelocytes, $8 \%$ metamyelocytes, $10 \%$ neutrophil bands, $45 \%$ segmented neutrophils, $3 \%$ eosinophils, $4 \%$ basophils, $8 \%$ lymphocytes, and $9 \%$ monocytes.

The bone marrow aspirate showed hypercellular particles and a left shift in the myelocyte peak, with $5 \%$ erythroid precursors, $2 \%$ myeloid blasts, $7 \%$ promyelocytes, $42 \%$ myelocytes, $23 \%$ metamyelocytes and bands, $18 \%$ neutrophils, and $3 \%$ eosinophils.

On flow cytometry analysis of the bone marrow, $84 \%$ of cells fell within the granulocyte gate, $8 \%$ in the nucleated red blood cell gate, and $2 \%$ each in the lymphocyte gate, CD45 dim gate, and monocyte gate. The gated population of CD45 dim cells showed partial expression of early markers CD117 and CD34, consistent with myeloid blasts ( $0.4 \%$ of total cell population).

Cytogenetic analysis was performed on bone marrow cells collected at the time of primary diagnosis and cultured using standard techniques. From this, twenty GTG banded metaphase cells were analyzed and all were found to possess a complex, three-way (9;22;17)(q34.1;q11.2;q11.2) Philadelphia chromosome translocation (Fig. 1). Further analysis by fluorescence in situ hybridization (FISH) utilizing dual-color fusion probes confirmed the presence of Bcr-Abl translocation in 86 out of 100 interphase cells (Fig. 2).

\section{Discussion}

The Philadelphia chromosome $\mathrm{t}(9 ; 22)(\mathrm{q} 34 ; \mathrm{q} 11)$ is present in greater than $90 \%$ of CML patients, however approximately $5 \%$ of patients demonstrate variants in which a third chromosome in addition to chromosomes 9 and 22 is also involved (1). These complex three-way translocations could be formed by two mechanisms. Either there could be a one-step translocation 


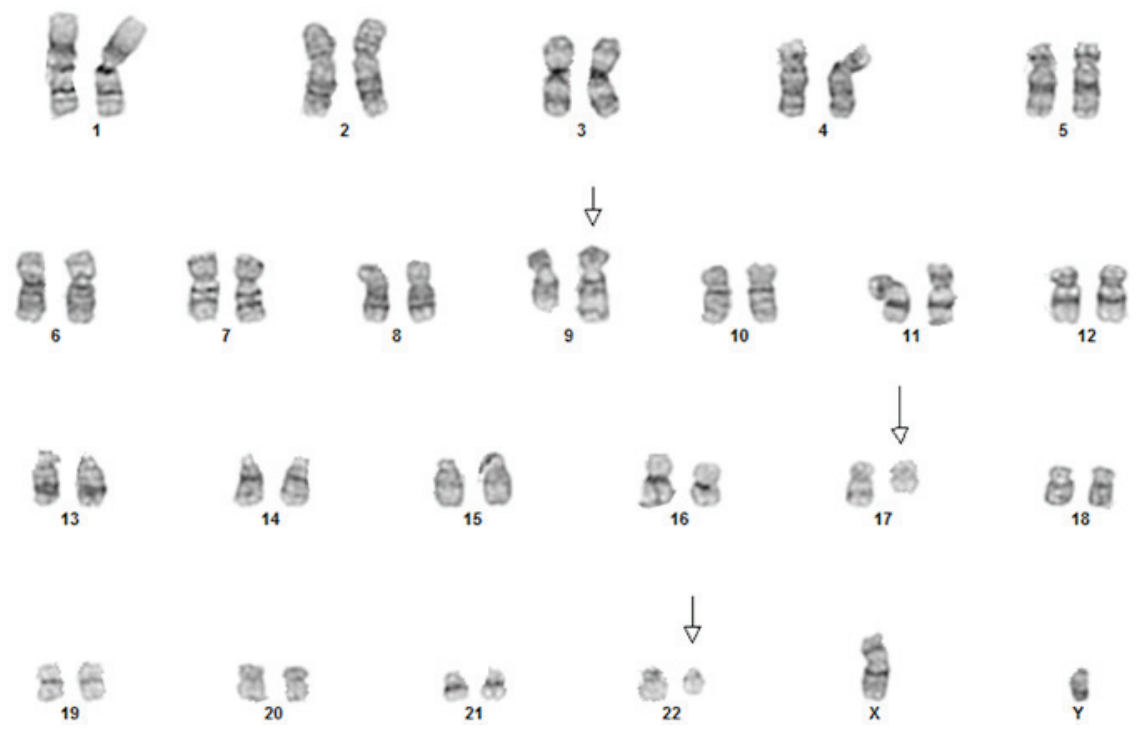

Figure 1. G-banded karyotype showing 46, XY, t(9;22;17)(q34.1;q11.2;q11.2).

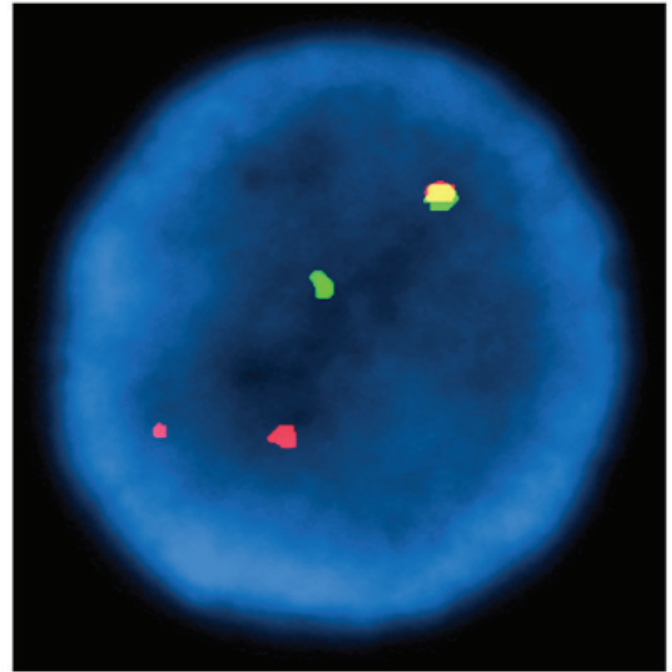

Figure 2. Dual-color fluorescence is situ hybridization probe showing one green $(\mathrm{Bcr})$ signal on chromosome 22, one large orange (Abl) signal on chromosome 9, one yellow fusion signal (Bcr-Abl), and a small orange signal showing the residual $\mathrm{Abl}$ on chromosome 9. This confirms the presence of Philadelphia chromosome translocation.

involving three chromosomes at the same time, or a two-step mechanism where first a typical $t(9 ; 22)$ translocation occurs, followed by a second translocation between the aberrant chromosome 9 or 22 and the 3 rd chromosome (2). The most frequently involved chromosomes in variant Philadelphia translocation are $3 \mathrm{p} 21,3 \mathrm{q} 21,11 \mathrm{q} 13,12 \mathrm{p} 13$, and $17 \mathrm{q} 25$ (3). Other chromosomes that have been rarely involved in variant Philadelphia translocation include 4q25 (4), 10p11.2 (5), $11 \mathrm{p} 15$ (6), 17p11.2 (7), and 21p12 (8). One uniting factor, however, is that all of these variants ultimately lead to a Bcr-Abl fusion gene $(3,9)$. The exact translocation present in our patient has not been previously reported, however analysis by FISH confirmed the presence of a Bcr-Able fusion gene.

The clinical presentation of CML patients with variant Philadelphia chromosomes is indistinguishable from that of patients with the classic translocation. Additionally, several reports have found that Philadelphia chromosome variant patients tend to have a similar prognosis to those with the classic Philadelphia translocation when treated with imatinib therapy (10).

In conclusion, we report a rare case of chronic phase CML with a novel complex three-way Philadelphia variant $\mathrm{t}(9 ; 22 ; 17)$ (q34;q11.2,q12).

\section{References}

1. Asif M, Hussain A, Malik A and Rasool M: Three-way complex variant translocation involving short arm chromosome $(1 ; 9 ; 22)$ (p36;q34;q11) in a chronic myeloid leukemia patient. Oncol Lett 10: 1728-1730, 2015.

2. Tanaka K, Minamihisamatu M, Yagi SH, Kyo T, Dohy H and Kamada N: Two step mechanism for formation of complex 9;22 chromosome translocation in chronic myelocytic leukemia detected by fluorescence in situ hybridization. Exp Oncol 23: 29-38, 2001.

3. Dierlamm J, Michaux L, Stefanova M, Eggert J, Leberecht P, Seeger D, Westerhausen M and Hossfeld DK: Novel Philadelphia variant $\mathrm{t}(\mathrm{Y} ; 9 ; 22)(\mathrm{q} 12 ; \mathrm{q} 34 ; \mathrm{q} 11)$ in a case of chronic myeloid leukemia. Cancer Genet Cytogenet 114: 150-153, 1999.

4. Sheth FJ, Sheth JJ and Verhest A: A three way complex translocation $(4 ; 9 ; 22)$ in two patients with chronic myelocytic leukemia. J Cancer Res Ther 1: 108-110, 2005.

5. Al-Achkar W, Wafa A, Ikhtiar A and Liehr T: Three-way Philadelphia translocation $\mathrm{t}(9 ; 10 ; 22)(\mathrm{q} 34 ; \mathrm{p} 11.2 ; \mathrm{q} 11.2)$ as a secondary abnormality in an imatinib mesylate-resistant chronic myeloid leukemia patient. Oncol Lett 5: 1656-1658, 2013.

6. Asif M, Hussain A and Rasool M: A rare case of a three way complex variant positive Philadelphia translocation involving chromosome $(9 ; 11 ; 22)(\mathrm{q} 34 ; \mathrm{p} 15 ; \mathrm{q} 11)$ in chronic myeloid leukemia: A case report. Oncol Lett 12: 1986-1988, 2016.

7. Kokate P, Dalvi R and Mandava S: A complex three-way translocation with deletion of the TP53 gene in a blast crisis chronic myeloid leukemia patient. J Cancer Res Ther 11: 1037, 2015.

8. Al-Achkar W, Wafa A, Moassass F and Liehr T: A chronic myeloid leukemia case with a unique variant Philadelphia translocation: $\mathrm{t}(9 ; 22 ; 21)(\mathrm{q} 34 ; \mathrm{q} 11 ; \mathrm{p} 12)$. Oncol Lett 3: 1027-1029, 2012.

9. Mitelman F and Heim S (eds): Cancer Cytogenetics: Chromosomal and Molecular Genetic Aberrations of Tumor Cells. 2nd edition, Wiley-Liss, Inc., New York, 1995.

10. Valencia A, Cervera J, Such E, Barragán E, Bolufer P, Fuster O, Collado R, Martínez J and Sanz MA: Complex variant $\mathrm{t}(9 ; 22)$ chromosome translocations in five cases of chronic myeloid leukemia. Adv Hematol 2009: 187125, 2019. 